\title{
ANNOTATION
}

\section{Reports of Blindness in Glasgow, 1926}

This report is issued under the authority of the Joint Committee for the South-west of Scotland for the administration of the Blind Persons Act, 1920. It is in two sections : (a) a statistical inquiry into the causes of loss of vision among the adult blind; and (b) a report on the social and economic conditions of blind persons. The Medical Officer of Health contributes an instructive introduction. We quote almost verbatim from this introduction.

The routine examinations were carried out by Dr. Freeland Fergus. The original idea was to survey the whole blind population of the areas represented on the Joint Committee, but the inquiry was interrupted as soon as the examination of the adult blind in the city of Glasgow had been completed by Dr. Freeland Fergus. This report deals with the city group, which comprises 1,206 adult btind persons out of a known figure of approximately 1,587 persons over 16 years of age, on the register of the blind.

The first section would appear to be the first inquiry into the causes of blindness at work in a large industrial area; the data have been analyzed and discussed in a comprehensive rather than in a brief and summarized manner.

A considerable group, at least 17 per cent., probably much greater, owe their disability to venereal disease. A prominent feature of the report is the way in which preventive measures are dwelt on; diminution in the incidence of syphilis is yearly taking place; while the importance of ante-natal treatment is stressed. One of the most illuminating things is the chart showing the increase in gonorrheal ophthalmia which took place during the war, and the very considerable decline which has followed since 1919.

Among other infections of the eye causing blindness, measles is responsible for 2.9 per cent. of blindness (35 cases); trachoma ( 7 cases); and meningitis (11 cases). Trachoma was made notifiable in Glasgow in 1914, and its treatment provided for at a special dispensary and in hospital.

Injuries as a cause of blindness accounted for 16 per cent. The inquiry revealed the unexpected result that the accidents of civilian life, to which children are specially liable, caused twice as many cases of blinding as did occupational injuries. There is room for propaganda as regards both prevention and treatment in this class of case.

Senile cataract appears third among the causes of blindness. In this series 60 of the cataract cases had had no operation, 
Points which emerge from this report are :

(1) Prevention of eye defects and blinding due to syphilis in adults depends on efficient treatment, -and in the case of children on efficient ante-natal treatment.

(2) Children suffering from eye defects which might result in defective vision and blindness should be kept under observation and appropriately treated.

(3) Prompt treatment of injuries to the eye, especially among children, might be aided by propaganda.

(4) The question of providing glasses in necessitous cases, where this would improve the eyesight of a blind person or lift him out of this category altogether might be considered.

The second section traverses ground which may be of service to the Committee from an administrative point of view. Under "Relation to Employment," a useful table is given in respect of 2,903 blind persons in Glasgow and the south-western counties administered by the Committee. Of these 177 are of school age and under, 227 are employed in institutions, 184 are under training, while 414 are otherwise employed. Two groups remain, comprising 198 persons returned as untrained but employable, and a large residual group of 1,703 included under the heading unemployable. This residual group contains 742 males and 961 females; many of the latter are married women. There would appear to be room for absorption into training of a proportion at any rate of those returned as employable. During the course of his examinations Dr. Freeland Fergus found a number of cases which, in his opinion, did not come within the definition of blindness as expressed in the Blind Persons Act. As regards admission to the register it would be advisable that in future this should be controlled by medical examination, and that in cases of doubt a specialist should be consulted. It would also be of advantage if the Board of Health were to determine what degree of ocular defect should entitle a person to be registered as blind so as to secure uniformity throughout the country, and to serve as a guide in border-line cases.

There is need for closer co-operation between voluntary agencies and the joint Committee; it would clear the position, especially as regards the outdoor blind, if the Joint Committee were to keep local registers containing such information as would be of service, especially on the economic and social side of the problem, so as to preserve continuity of information as to the condition and movement of blind persons.

This brief abstract of the Medical Officer of Health's observations in the preface gives, we fear, but an inadequate idea of the extreme importance of the report. We hope that it will be 
distributed broadcast over the whole country, and studied with care by all ophthalmic surgeons and by those who have anything to do, officially or voluntarily, with the care of the blind.

The remarks on prevention alone are worthy of wide dissemination.

Dr. Freeland Fergus and his colleagues are to be congratulated on an extremely valuable piece of work.

It is to be regretted that no indication is given as to where the report can be obtained or of its price.

\section{THE OPTICAL CONVENTION}

The Optical Convention was held at the Imperial College of Science and Technology, South Kensington, from April 12 to April 17. This was the third Optical Convention, the first having been held in 1905 and the second in 1912. The Convention of 1926 met under the presidency of the Astronomer Royal, Sir Frank Dyson, and was highly successful in dealing with a full and varied programme. The Transactions will form a very valuable record of the present position of the science and industry of optics in this country. The war, by throwing us on our own resources, caused us to make great advances in the production of optical apparatus, and thus enabled us to go far to regain the leadership that was rapidly passing into German hands.

While some of the papers were directly concerned with ophthalmic work, all contained some points of interest to the ophthalmologist. Professor Elliot Smith gave an interesting account of the eye and its functions in which he traced man's intellectual superiority to the evolution of his visual sense. Messrs. Chance and Hampton read a paper on the practical side of the manufacture of optical and tinted glass which included an account of a glass that had been produced after twenty years of experiment to serve as a filter that gave a spectroscopically correct colour match when used with a half-watt lamp. Of the various papers specially concerned with ophthalmic work that of Messrs. Hartridge and Lythgoe on the influence of illumination on visual acuity; of $\mathrm{Mr}$. Fincham on the mechanism of accommodation; and that of $\mathrm{Mr}$. Taylor on the fitting of glasses in cases of facial asymmetry were specially noteworthy. We hope to be able to give abstracts of some of the papers when published.

Especially noticeable was the collection of early telescopes, astrolabes, etc. The dispensing opticians held a remarkably fine exhibition of ophthalmic wares in a large room in the basement. 